\title{
$O$ agir professoral e o trabalho de professores em formação inicial representados em relatórios do projeto residência pedagógica
}

\author{
The teaching and the work of teacher in initial education \\ represented in reports of the pedagogical residency project
}

\author{
Rosivaldo Gomes \\ Universidade Federal do Amapá, Macapá, Amapá, Brasil \\ Eulália Vera Lúcia Fraga Leurquin \\ Universidade Federal do Ceará, Fortaleza, Ceará, Brasil
}

\begin{abstract}
Resumo: O objetivo deste texto centra-se em discutir representações do agir professoral e do trabalho de professores de Língua Portuguesa em formação inicial. De maneira mais específica, apresenta uma análise de segmentos de tratamento temáticos (BULEA, 2010) de dois relatórios escritos por acadêmicos participantes do Projeto Residência Pedagógica, subprojeto Letras/Língua Portuguesa, da Universidade Federal do Amapá. A base teórica fundamenta-se nas noções de trabalho docente, agir professoral (CICUREL, 2011; LEURQUIN, 2013) e nas categorias da Semântica do Agir do quadro do Interacionismo Sociodiscursivo (BRONCKART, 2008; 2006; MACHADO; BRONCKART, 2009; BRONCKART; MACHADO, 2004). O estudo caracteriza-se como qualitativo-interpretativista e situa-se no campo da Linguística Aplicada. Os resultados demonstram que as/os professoras/es em formação, a partir de seu agir professoral, planificam e ressignificam seu trabalho realizado em sala de aula não somente com base no que está prescrito em documentos oficiais voltados para o ensino de Língua Portuguesa, mas também em função das necessidades de ensino que se deparam nas escolas e das necessidades e possibilidades de aprendizagem dos alunos.
\end{abstract}

Palavras-chave: Agir professoral; Formação inicial; Ensino

\begin{abstract}
The objective of this text is to discuss representations of the teaching activity and the work of Portuguese language teachers in initial education. More specifically, it presents an analysis of thematic treatment segments (BULEA, 2010) of two reports written by academics participating in the Pedagogical Residency Project, subproject Letters / Portuguese Language, of Federal University Amapá. The theoretical basis is grounded on the notions of teaching work, acting as teachers (CICUREL, 2011; LEURQUIN, 2013) and on the categories of Semantics of Acting within the framework of Sociodiscursive Interactionism (BRONCKART, 2008; 2006; MACHADO; BRONCKART, 2009; BRONCKART; MACHADO, 2004). The study is characterized as qualitative-interpretativist and is in the field of
\end{abstract}

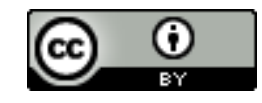


Applied Linguistics. The results show that pre-service teachers, based on their teaching actions, plan and resignify their work in the classroom not only based on what is prescribed in official documents aimed at teaching Portuguese as a foreign language, but according to the teaching needs that are encountered in schools and the students' needs and learning possibilities as well.

Keywords: Acting professor; Initial Training; Teaching

\section{Introdução}

O agir professoral (CICUREL, 2011; LEURQUIN, 2013) e o trabalho desenvolvido pelo professor, a partir desse agir nas interações de sala de aula, têm sido foco de alguns estudos na Linguística Aplicada (LA) no contexto brasileiro e em outros campos no contexto estrangeiro. Nesse sentido, os estudos desenvolvidos sobre esses temas, em grande medida, fundamentam-se nas abordagens teóricas da Clínica da Atividade (CLOT, 2007), da Ergonomia da Atividade (AMIGUES, 2004; SAUJAT, 2004) e em variados conceitos oriundos do quadro epistemológico do Interacionismo Sociodiscursivo (ISD) (BRONCKART, 2006, 2008), como por exemplo, a noção de representação do agir na e pela linguagem.

Além disso, esses estudos mostram que o trabalho do professor e o seu agir professoral configuram-se como ações complexas que envolvem diversas questões relativas a dimensões pessoais, educacionais, sociais, políticas, governamentais e estruturais, as quais estão intrinsecamente relacionadas (LEURQUIN, 2013). Dessa maneira, o objetivo deste artigo é discutir o trabalho docente e o agir professoral desenvolvidos por professores de Língua Portuguesa em formação inicial - aqui denominados de professores-residentes - a partir de representações desse trabalho em relatórios de atividades didáticas, elaborados por dois grupos de acadêmicos participantes do governo federal Residência Pedagógica, subprojeto de Letras/Língua Materna, coordenado pela Universidade Federal do Amapá, no ano de 2019 e desenvolvido em duas escolas públicas de educação básica da cidade de Macapá.

O estudo caracteriza-se como qualitativo-interpretativista (DENZIN; LINCOLN, 2006) e situa-se no campo da LA. Para atender ao objetivo proposto, buscamos responder ao seguinte questionamento: a) Como os professores-residentes, participantes do Projeto 
Residência Pedagógica, representam em seus discursos o trabalho e o agir professoral por eles desenvolvidos durante suas experiências de sala de aula? ${ }^{1}$

Para a realização da análise, buscamos aportes nas categorias do Semântica do Agir (BRONCKART, 2008; 2006; MACHADO; BRONCKART, 2009; BRONCKART; MACHADO, 2004), sendo consideradas as dimensões do agir: motivacional, intencional e no plano dos recursos para o agir, tal como discutido no campo do ISD. O artigo está estruturado em quatro momentos, além da introdução e das considerações finais: i) dimensões do trabalho docente; ii) categorias da Semântica do Agir; iii) aspectos metodológicos; e iv) análise dos dados, quando apresentamos o trabalho dos professores em formação e o agir professoral representados nos relatórios.

\section{Dimensões do trabalho docente e o agir professoral}

No quadro teórico do ISD, a noção de trabalho, configurada como uma forma de agir, ou prática característica da espécie humana (BRONCKART, 2008, p. 93), aparece fundamentada nas contribuições teóricas das Ciências do Trabalho, principalmente, da Clínica da Atividade e da Ergonomia da Atividade. Nos estudos ergonômicos, a concepção de trabalho aparece relacionada à ideia de tarefa. Para Amigues (2004), uma tarefa constitui-se como o que deve ser feito e pode ser explicado em termos de objetivos e de meios utilizados pelo sujeito para sua realização.

Relacionado a estes dois termos - tarefa e atividade -, no campo da Ergonomia, a noção de trabalho aparece fundamenta-se a partir de duas dimensões: a) a dimensão do trabalho prescrito e a dimensão do trabalho realizado. O trabalho prescritivo configura-se como a forma, a maneira, isto é, as orientações/prescrições que direcionam as tarefas do trabalhador (MACHADO, 2004, 2009), as quais são instituídas por instâncias empresariais e/ou governamentais. Na visão de Bronckart (2006, p. 208), trata-se, neste caso, de "uma representação do que deve ser o trabalho, que é anterior à sua realização efetiva". Com relação à realidade do trabalho educacional (BRONCKART, 2006), no quadro do ISD, o trabalho prescrito do professor é compreendido como aquele que é

\footnotetext{
${ }^{1}$ Este artigo resulta de uma pesquisa de pós-doutoramento desenvolvida no Programa de Pós-graduação da Universidade do Ceará, no âmbito do Grupo Gepla, sob a supervisão da segunda autora.
} 
instituído com base em documentos, neste caso textos prefigurativos (BRONCKART, 2006) ou textos de prescrição do trabalho ou de trabalho prescrito por órgãos governamentais.

Todavia, vale salientar que o professor se apropria dessas prescrições, as adapta e as (re)configura a partir de suas necessidades de ensino, bem como das necessidades de aprendizagem dos alunos, das condições de trabalho que lhe são oferecidas e de sua formação. Trata-se, portanto, de reconcepções (MACHADO; LOUSADA, 2010; AMIGUES, 2004) ou de autoprescrições (MACHADO; LOUSADA, 2010) realizadas pelo professor para condução de seu métier.

Como desdobramento do trabalho prescrito, Machado (2004, 2009), em seus estudos, propõe a dimensão do trabalho planificado, que corresponde ao "conjunto das tarefas, seus objetivos, suas condições materiais e sua forma de desenvolvimento das ações projetadas pelo próprio trabalhador" (MACHADO, 2009, p. 81). Já o trabalho realizado está relacionado com o que foi desenvolvido com base em prescrições que são estabelecidas para o trabalhador ou por ele reconfiguradas. No caso do trabalho educacional do professor, essa dimensão diz respeito ao que foi desenvolvido em sala de aula pelo docente a partir de seu agir professoral e da mobilização de um repertório didático, sendo esse trabalho e agir passíveis de serem observados e analisados, tendo-se por base registros das condutas verbais e não verbais do professor durante a realização de uma ação didática em sala de aula.

Além dessas dimensões, no quadro da Clínica da Atividade, há a dimensão do real da atividade (ou trabalho real), que, apesar de se basear na definição estabelecida pelos ergonomistas, recebe outra acepção. Para Clot (2007), o trabalho real não inclui apenas o que foi feito pelo trabalhador, mas o que foi desejado para ser realizado. Ou seja, aquilo que o trabalhador teria, deveria, poderia e queria ter feito, mas que, por fatores relativos às condições de trabalho, a sua formação e devido a outros determinantes, tanto externos quanto internos, não foi possível de ser feito (LEURQUIN, 2013; CLOT, 2007).

Acrescentamos a esse conjunto de dimensões o trabalho representado (avaliativo ou interpretado pelos actantes) e o trabalho interpretado por observadores externos, conforme propõe Bronckart $(2006,2008)$. O trabalho representado diz respeito a reflexões realizadas pelo trabalhador antes ou depois da realização de uma tarefa. No contexto educacional, o trabalho representado pode ser compreendido como as 
representações que o professor tem sobre sua prática antes ou depois da realização de ações didáticas em sala de aula.

Desse modo, é no trabalho representado que professor pode fornecer indícios sobre o trabalho por ele realizado e planejado, pois conforme salienta Bronckart (2008) os textos apresentam representações do trabalho, em nosso caso, do trabalho docente e podem mostrar o que emerge da consciência discursiva dos trabalhadores (professores) em uma situação específica de reflexão e atuação. Quanto à dimensão do trabalho interpretado por observadores externos, de acordo com Bronckart (2008), essa dimensão comporta textos ou segmentos relativos à construção verbal de ações sobre o ângulo de pesquisadores externos ao trabalho realizado pelo professor.

O conjunto dessas dimensões mostra-nos que o trabalho do professor configurase de forma complexa, sendo que a compreensão delas pode auxiliar o próprio docente, em processo de formação e em desenvolvimento profissional, ou já formado e em serviço, na reflexão sobre seu trabalho, bem como auxiliar pesquisadores no entendimento de indícios textuais e discursivos, presentes em textos sobre e do trabalho docente, a compreenderem representações que os professores constroem sobre suas práticas/ações nas interações didáticas em sala aula. Nesse sentido, Machado (2007) e Bronckart (2008), ao ressaltarem que o trabalho do professor é uma forma de agir no mundo, destacam que esse trabalho se caracteriza de forma situada, prefigurada, mediada, pessoal, interacional, interpessoal, transpessoal e conflituosa.

Dessa maneira, conforme Machado (2007), podemos pensar o trabalho do professor considerando a mobilização que esse sujeito faz de seu ser integral, tendo em vista as diferentes situações com as quais se ele envolve para a realização de seu métier (planejamento, aula, avaliações). Além disso, o professor deve dar conta de seu objetivo maior que é o de criar um meio que possibilite aos alunos a aprendizagem de um conjunto de conteúdos de sua disciplina e o desenvolvimento de capacidades específicas relacionadas a esses conteúdos.

O professor deve orientar-se, por um projeto de ensino que lhe é prescrito por diferentes instâncias superiores e com a utilização de instrumentos obtidos do meio social e com base na interação com outros instrumentos e sujeitos que, de forma direta ou indireta, estão envolvidos na situação de ensino (MACHADO, 2007, p. 93). O trabalho do professor se configura, dessa forma, como uma complexa rede de relações sociais, 
constituído em um determinado contexto sócio-histórico maior, envolvido com um sistema de ensino e com um sistema educacional específico.

A esse modo de compreender o trabalho docente, acrescentamos a visão de Leurquin (2013) que entende o agir do professor com base na mobilização de saberes, instrumentos, ferramentas, etc. e de um repertório didático que esse sujeito faz para e na realização de seu trabalho. Todavia, consideramos que na e para a constituição desse agir estão presentes modalizadores, isto é, um dever-saber, um querer-fazer e um poder-fazer, os quais, em alguma medida, relacionam-se com o desenvolvimento ou não do trabalho do professor. Nesse sentido, para a autora

\begin{abstract}
No seu agir professoral, o professor mobiliza um conjunto de saberes e um saber-fazer (já esperado, devido ao papel que ele assume na sala de aula; pelo trabalho que ele se propõe a realizar). Todavia, ele também mobiliza um deversaber, um querer-fazer e um poder-fazer (pelo compromisso que assume na sociedade e pelas condições, pelos objetivos, pela vontade/interesses, etc., em jogo), reconhecendo a carga semântica que cada ação dessas possa ter. Para compreender o agir professoral nesta perspectiva, também é necessário entender os mundos representados (mundo físico, mundo subjetivo e mundo social), como propõe Bronckart (1999). A necessidade de se fazer essas ponderações decorre do fato de que o agir professoral tem base na interação; é mediado pela linguagem; e é diferente de qualquer outro agir, pois se realiza em uma situação de ensino e em situação ou não de formação. (LEURQUIN, 2013, p. 309-310).
\end{abstract}

Partindo da visão proposta por Leurquin (2013), compreendemos que em seu trabalho o professor mobiliza/realiza um agir professoral que se desenvolve na interação com outros sujeitos e que, portanto, não se limita à sala de aula. Dessa maneira, o professor realiza outras ações como preparação de aula, correção de exercícios, avaliações, reuniões, estudos coletivos, isto é, ações que extrapolam a sala de aula, sendo que esse sujeito também é interpelado por determinantes externos ao contexto das práticas do letramento escolar, os quais limitam tanto o seu trabalho quanto o seu agir professoral em certas ocasiões. Assim, concordamos com a visão de Leurquin (2013) de que para entender o agir professoral é preciso compreender que ensinar é/deve ser visto como uma maneira mais ampla, interativa e complexa, pois trata-se de um conjunto formado por ações que estão em jogo e que envolvem outros determinantes externos à prática de sala de aula. 


\section{A Semântica do Agir: categoria analítica para o agir e o trabalho professoral}

Nesta seção, apresentamos as categorias que nos auxiliaram no percurso analítico dos dados. No contexto do ISD, a Semântica do Agir ou Semiologia do Agir (BRONCKART, 2006, 2008) apresenta como conceitos centrais as noções de: agir ou agir-referente, atividade, ação, dimensões/planos do agir: motivacional, intencional, recursos do/para o agir e os seres humanos que intervêm no agir: actante, ator e agente. Como alguns desses conceitos já são bastante conhecidos e utilizados em pesquisas brasileiras, que consideram o quadro epistemológico do ISD, nos deteremos apenas nas dimensões/planos envolvidas no agir, as quais foram consideradas como categorias de análise.

Para Bronckart (2006, 2008) e Bronckart e Machado (2004), a dimensão/plano motivacional constitui-se por determinantes externos, de origem coletiva, de natureza material ou da constituição de representações sociais; e por motivos, que se configuram como as razões do agir interiorizadas por uma pessoa particular. Já na dimensão/plano da intencionalidade, os autores distinguem as finalidades, caracterizadas como a origem coletiva e socialmente validadas para o agir; e as intenções, que são os fins do agir, tais como são interiorizadas por uma pessoa em especial.

Por fim, na dimensão/plano dos recursos para o agir Bronckart e Machado (2004, p. 155) distinguem os instrumentos, que podem ser ferramentas concretas ou modelos do agir, disponíveis no meio social, das capacidades, que são os recursos mentais ou comportamentais que se atribuem a uma pessoa particular. Considerando essas dimensões, na próxima seção, apresentamos o percurso metodológico do estudo.

\section{Procedimentos metodológicos}

O estudo situa-se no campo da LA e se caracteriza como qualitativo-interpretativista (DENZIN; LINCOLN, 2006; BORTONI-RICARDO, 2008), uma vez que interessa-nos compreender as representações atribuídas pelos professores-residentes, participantes do Projeto Residência Pedagógica, ao trabalho e ao agir professoral por eles desenvolvidos durante suas atuações nas aulas de Língua Portuguesa nas escolas participantes do projeto. O corpus analisado é constituído por dois relatórios, aqui denominados de Relatório 1 
(RL1) e Relatório 2 (RL2), referentes às atividades realizadas por dois grupos de professores-residentes, durante as atividades de ensino do subprojeto de Letras/Português, o qual foi desenvolvido na Universidade Federal do Amapá e coordenado pelo primeiro autor deste artigo, no período de agosto de 2018 a janeiro de 2019.

Os textos analisados - relatórios - estão sendo compreendidos, neste estudo, como textos-fonte que tratam sobre o trabalho docente, isto é, que foram produzidos pelos próprios professores-residentes após a realização de uma determinada tarefa (BRONCKART, 2006, 2008) e que, portanto, apresentam representações do agir professoral referente ao trabalho planejado e realizado de seus produtores. Para a análise, consideramos apenas alguns Segmentos de Tratamento Temático (STT) dos relatórios nos quais são apresentadas representações agir professoral dos professores, durante o curso do agir, isto é, tanto durante a elaboração de materiais didáticos (, quanto durante a realização da aulas por eles/as ministradas nas escolas-campo do projeto.

\section{0 agir professoral e trabalho docente dos professores-residentes representados em relatórios}

Iniciamos a análise dos dados a partir das representações presentes nos relatórios no que diz respeito ao trabalho planificado. Os dois relatórios analisados foram elaborados por uma dupla e por um trio de professores residentes. Para compreensão da organização dos relatórios, apresentamos o quadro a seguir: 1) identificação do relatório (RL1 e RL2) e de seus produtores ${ }^{2}$; 2) ano da turma de atuação dos residentes; 3) conteúdos trabalhados a partir dos eixos de ensino selecionados e 4) projeto temático de intervenção realizado.

Quadro 1: Sistemática de organização dos relatórios

\begin{tabular}{|c|c|c|c|}
\hline $\begin{array}{c}\text { IDENTIFICAÇÃ } \\
0\end{array}$ & ANO & CONTEÚDOS & $\begin{array}{c}\text { PROJETO DE } \\
\text { INTERVENÇÃO }\end{array}$ \\
\hline $\begin{array}{c}\text { RL1 } \\
\text { Brenda } \\
\text { Paula } \\
\text { Gustavo }\end{array}$ & $\begin{array}{l}6^{\circ} \text { ano } \\
\text { do E.F. II }\end{array}$ & $\begin{array}{c}\text { Gênero textual cartaz } \\
\text { Concordância nominal } \\
\text { Práticas de produção escrita e leitura }\end{array}$ & $\begin{array}{l}\text { Produzindo o gênero } \\
\text { cartaz nas aulas de } \\
\text { Língua Portuguesa }\end{array}$ \\
\hline $\begin{array}{c}\text { RL } 2 \\
\text { Carla } \\
\text { Amanda }\end{array}$ & $\begin{array}{l}1^{\circ} \text { ano } \mathrm{E} . \\
\text { Médio }\end{array}$ & $\begin{array}{c}\text { Carta do Leitor } \\
\text { Práticas de produção escrita e leitura }\end{array}$ & $\begin{array}{l}\text { Trabalhando com gênero } \\
\text { Carta do Leitor }\end{array}$ \\
\hline
\end{tabular}

Fonte: elaborado pelos autores.

\footnotetext{
${ }^{2}$ Por questões éticas da pesquisa, os professores-residentes estão sendo identificados com nomes fictícios.
} 
O conjunto das informações, presentes no quadro 1 , já de início, fornece algumas pistas a respeito do trabalho planificado que fora desenvolvido pelos professores residentes. Assim, do ponto de vista da caracterização desse trabalho, para a planificação das atividades foram selecionados pelos professores-residentes dois gêneros textuais que estão diretamente relacionados com algumas práticas de linguagem/eixos de ensino propostas por documentos oficiais que prescrevem o ensino de Língua Portuguesa no contexto brasileiro.

Além disso, a escolha por esses gêneros e eixos não ocorre de maneira aleatória, pois nos relatórios há segmentos que tematizam representações do agir professoral desses sujeitos em relação a essa opção de gêneros, conforme observamos em alguns segmentos os quais foram retirados da seção que apresenta o desenvolvimento das atividades didáticas, mais especificamente da parte relativa à descrição da intervenção didática realizada. Nessa seção, esses atores (professores-residentes) representam, discursivamente, a caracterização do trabalho planificado que realizaram, apresentando assim os saberes prescritivos que por eles foram mobilizados para a elaboração do planejamento das ações didáticas e descrevem o agir professoral deles quanto à intervenção que foi realizada em sala de aula.

Nos segmentos a seguir, retirados de RL1 e RL2, vemos que a caracterização do trabalho planificado dos professores-residentes é fortemente influenciado por determinantes externos (BRONCKART; MACHADO, 2004), neste caso, por orientações que são estabelecidas por instâncias governamentais e por documentos oficiais, como, por exemplo, a BNCC, conforme os destaques em negrito.

\footnotetext{
RL1

STT1 -

STT1.1.1 (...) as atividades que compõem o projeto e que foram desenvolvidas no decorrer da regência contaram com a aplicação do tema referente ao gênero textual 'Cartaz' em conjunto com o conteúdo de concordância nominal. Optamos em trabalhar com esses conteúdos pois ambos estão presentes na disciplina de Língua Portuguesa do $6^{\circ}$ ano do ensino fundamental - anos finais e em função do pouco tempo disponibilizado pelas professora (...) a escolha do gênero cartaz subsidiou-se também a partir da recomendação da Base Nacional Comum Curricular, a qual orienta que é fundamental que o aluno do $6^{\circ}$ ao $9^{\circ}$ ano do ensino fundamental desenvolva habilidades de (...) o planejamento das atividades foi elaborado também de acordo com 0 caderno de planejamento da professora regente da turma para que, dessa maneira, pudéssemos dar continuidade aos conteúdos que ela já estava desenvolvendo.
} 


\begin{abstract}
RL2
STT1 -

STT1.1.1: O projeto desenvolvido fez parte das atividades propostas no Projeto Residência Pedagógica e foi aplicado em uma turma de $1^{\circ}$ ano do Ensino Médio da Escola XXXXXXX, no período de 07 (sete) de outubro de 2019 a 04 (quatro) de novembro do mesmo ano. $\mathrm{O}$ trabalho desenvolvido teve como objetivo contribuir para um aprofundamento de alguns gêneros textuais do campo de atuação jornalístico-midiático, especificamente a carta do leitor, seguindo o que está proposto na BNCC do Ensino Médio sobre o conhecimento dos gêneros que perpassam por esse campo de atuação, pois esse é o principal instrumento teórico utilizado para o ensino de língua portuguesa atualmente (...) apresentamos as características do gênero e os elementos linguístico-gramaticais que podem ser identificados na carta do leitor. Trabalhamos mais esses conteúdos pois a professora precisava também dar continuidade ao assunto que já havia iniciado com os alunos e aí incluímos questões de coesão textual também (...).
\end{abstract}

Além desses determinantes externos, estão implicados, no desenvolvimento do agir professoral relativo ao trabalho de planificação dos professores, outros determinantes que dizem respeito ao sistema de ensino local, neste caso, instâncias como a escola e a Secretaria de Estado da Educação do Amapá (SEED-AP), as quais determinam quais conteúdos devem ser tratados a partir da matriz curricular do $6^{\circ}$, como pode ser observado em RL1. Há ainda as "prescrições" propostas por outro agente, neste caso, pela própria professora que sugere/propõe que os professores-residentes deem continuidade a alguns conteúdos que ela estava trabalhando, como é evidenciado nos segmentos com sublinhado simples nos dois STT anteriores e, também, o pouco tempo disponibilizado para a realização das atividades, como é o caso do descrito em RL1 (com destaque sublinhado duplo).

Esses dados nos mostram que ao recorrerem à $\mathrm{BNCC}$ e às demais prescrições, durante o curso do agir (BRONCKART, 2008), os professores-residentes reconhecerem a importância desse documento e o que a escola propõe como objetos de ensino que devem trabalhados em sala de aula. As prescrições não são, portanto, descartadas e nem os saberes prescritivos oriundos delas, os quais fundamentam o ensino de língua materna/portuguesa no contexto em que esses actantes estão vivenciando práticas de desenvolvimento profissional. Ou seja, as prescrições de documentos oficiais são fundamentais tanto para o desenvolvimento do trabalho de planificação que os professores realizaram quanto para o trabalho realizado, pois apresentam direcionamentos sobre o saber-fazer (LEURQUIN, 2013), mas somente esse saber não é suficiente. 
Desse modo, nos textos/seguimentos em análise, observamos que os professoresresidentes apesar de recorrem à $\mathrm{BNCC}$ e às demais prescrições não se colocam como meros "tarefeiros", que consideram tais prescrições de forma ipsis litteris, mas realizam adequações, recortes, reconfigurações, elaboram tarefas dirigidas aos alunos, ou seja, realizam reconcepções (AMIGUES, 2004; SAUJAT, 2004; MACHADO; LOUSADA, 2010) desse documento.

Essas reconcepções/readequações, conforme podemos ver nos segmentos a seguir, estão relacionadas também com a intencionalidade do agir professoral dos professores-residentes, principalmente no que diz respeito às alterações feitas em seus planejamentos em função das reais necessidades de aprendizagem dos alunos, conforme vemos nos STT com destaques em itálico e sublinhado duplo:

\section{RL1}

STT2 -

STT2.2.: (...) esses primeiros planos foram elaborados com base em um material que nós consultamos da Revista Nova Escola, dos quais adaptamos alguns objetivos para o desenvolvimento de nossas aulas com o gênero cartaz e atividades, a partir de um fascículo didático elaborado. Porém, durante a observação foi possível constatar algumas dificuldades dos alunos para leitura e compreensão de textos e questões gramaticais que a professora trabalhava em sala de aula (...) a partir dessas constatações e com base em algumas competências e habilidades retiradas da BNCC e adequadas de acordo como nível da turma e também da necessidade dos alunos, alteramos os planos e também algumas atividades do fascículo didático (...).

\section{RL2}

STT2 -

STT2.2.1: Na realização da intervenção utilizamos uma Sequência Didática (...) criamos e organizamos planos de aula, contendo os objetivos para o ensino e que guiaram a elaboração de um conjunto de atividades didáticas (...) as atividades foram organizadas em 7 (sete) módulos e foram trabalhados em um total de 6 (seis) aulas. As atividades que elaboramos para a SD foram de práticas de leitura, prática de análise e de práticas de produção textual, trazendo as características do gênero carta do leitor. Nesse sentido, construímos as atividades a partir de um conjunto de habilidades da BNCC que foram adaptadas de acordo com a necessidade da turma, pois durante a observações percebemos um nivel baixo de proficiência em leitura (...).

Além dos determinantes que marcam a caracterização e a intencionalidade do trabalho e do agir professoral dos professores-residentes, vemos também alguns recursos usados por eles, isto é, instrumentos/ferramentas ou modelos que são mobilizados para concretização do trabalho realizado, conforme os segmentos a seguir (em negrito e itálico), além daqueles apresentados nos segmentos anteriores (Revista Nova Escola, fascículo didático, no caso de RL1 e uma SD, no caso de RL2): 
RL1

STT3 -

STT3.3.1: Para desenvolver as atividades foram criados quatro planos de aula com dois planos com duas aulas cada um e mais dois planos com apenas uma aula, totalizando seis aulas com duração de duzentos e oitenta minutos. Esses planos foram fundamentais, pois nos auxiliaram no desenvolvimento das aulas e das atividades que realizadas com os alunos juntamente com a Sequência didática elaborada (...).

RL2

STT3 -

STT3.3.1: (...) também consideramos algumas atividades do livro do portal do professor do $\mathbf{M E C}$, mas vimos que as atividades precisavam ser melhoradas, pois não aprofundavam o gênero carta (...) e usamos o livro didático usado pela professora, que apresentava um capítulo com uma proposta didática para produção do gênero carta de leitor e que julgamos ser adequada para o trabalho de escrita com os alunos (...).

Com base nos STT acima, vemos que o trabalho realizado, a partir do agir dos professores-residentes, se desenvolveu com base em dois eixos. O primeiro diz respeito à utilização dos planos de aula que apresentaram direcionamentos (objetivos didáticos) e orientaram o saber-fazer das/os professores no momento da intervenção em sala de aula. Já o segundo, diz respeito às atividades de práticas, ora elaboradas pelos professoresresidentes, ora a partir de adaptações e/ou consultas a materiais como livros didáticos e atividades de domínio público postadas no Portal do Professor do Ministério da Educação.

Isso mostra que tal postura os ajuda a constituírem suas profissionalidades e capacidades de pilotarem um projeto de ensino (BRONCKART, 2006) adequado às necessidades de aprendizagem das/os alunas/os, mas também evidencia a necessidade de se colocarem como autores de seus próprios materiais didáticos.

\section{Considerações finais}

Retomando ao objetivo proposto neste artigo - discutir algumas representações do agir professoral e do trabalho de professores de Língua Portuguesa em formação inicial - a análise dos dados, fundamentada a partir da semântica do agir, permitiu-nos compreender, no caso em estudo, que a dimensão relativa ao agir professoral e ao trabalho tanto planificado e quanto realizado (MACHADO, 2005), desenvolvidos pelas/os professoresresidentes, configuram-se a partir de determinantes externos que estão ligados 
diretamente com prescrições que são estabelecidas a partir de documentos oficiais, com intenções e modelos de agir que esses sujeitos se apoiam para a concretização de seu métier.

A respeito desses pontos, vemos que, apesar de as prescrições serem consideradas pelos atores implicados no agir professoral, isso não anula a autonomia desses sujeitos no que diz respeito à planificação e à modelização didática que realizam para o trabalho desenvolvido em sala de aula a partir do que foi projetado/planejado.

Isso mostra também que o professore em formação apresenta consciência a respeito da necessidade de conhecer e mobilizar saberes oriundos dessas prescrições, mas, também reconhece, a necessidade de adaptá-los às necessidades de seu contexto de ensino e às necessidades de aprendizagem dos alunos. Além disso, vemos que ao tematizarem tanto a caracterização quanto a preparação e o desenvolvimento do agir (a tarefa de planejar os planos de aulas, as atividades e ministrar aulas), os professores-residentes apreenderam o agir em sua singularidade, portanto, mobilizam saberes teóricos e práticas no dialógico com aquilo que foi observado no contexto de atuação das escolas-campo e sala de aula.

\section{Agradecimentos}

R.G. contou com apoio de bolsa do Programa Nacional de Pós-doutorado da Coordenação de Aperfeiçoamento de Pessoal de Nível Superior (PNPD/CAPES).

\section{Contribuição}

Rosivaldo Gomes: Escrita - análise e edição; Eulália Vera Lúcia Fraga Leurquin: Escrita - análise e edição.

\section{Referências}

AMIGUES, R. Trabalho do professor e trabalho de ensino. In: MACHADO, A. R. (org.) O ensino como trabalho: uma abordagem discursiva, Londrina: EDUEL: 35-54, 2004.

BORTONI-RICARDO, S. M. O professor pesquisador: introdução à pesquisa qualitativa. São Paulo: Parábola Editorial, 2008. 
BRONCKART, J. P. Atividade de linguagem, textos e discursos: por um interacionismo sociodiscursivo. 2.ed. São Paulo: Educ, 2009.

BRONCKART, J. P.; MACHADO, A. R. Procedimentos de análise de textos sobre o trabalho educacional. In: MACHADO, A. R. (Org.). O ensino como trabalho: uma abordagem discursiva. Londrina: Eduel, 2004. p. 131-163.

BRONCKART, J. P. Atividade de linguagem, discurso e desenvolvimento humano. Tradução Anna Rachel Machado, Maria de Lourdes Meirelles Matencio. Campinas-SP: Mercado das Letras, 2006.

BRONCKART, J. P. O agir nos discursos: das concepções teóricas às concepções dos trabalhadores. Tradução Anna Rachel Machado e Maria de Lourdes Meirelles Matencio. Campinas-SP: Mercado de Letras, 2008.

BULEA, E. Linguagem e efeitos desenvolvimentais da interpretação da atividade. Campinas, São Paulo: Mercado de Letras, 2010.

CICUREL, F. Les interactions dans I' enseignement des langues: l'agir professoral, Didier, Paris, 2011.

CLOT, Y. A função psicológica do trabalho. 2 ed. Tradução de Adail Sobral. Rio de Janeiro, Petrópolis: Vozes, 2007.

DENZIN, N. K.; LINCOLN, Yvonna. A disciplina e a prática da pesquisa qualitativa. In: DENZIN, N. K.; LINCOLN, Y. (Org.). Planejamento da pesquisa qualitativa: teorias e abordagens. 2 ed. Porto Alegre: ARTMED, 2006.

LEURQUIN, E. V. L. F. O que dizem os professores sobre seu agir professoral?. In: Ana Flávia Lopes Magela Gerhardt. (Org.). Ensino-aprendizagem na perspectiva da Linguística Aplicada. Campinas: Pontes, 2013, v. 1, p. 299-332.

MACHADO, A. R. Por uma concepção ampliada do trabalho do professor. In: GUIMARÃES, A. M. M; MACHADO, A. R.; COUTINHO, A. (org.) O Interacionismo Sociodiscursivo: questões epistemológicas e metodológicas. São Paulo: Mercado de Letras, 2007, p. 77-97.

MACHADO, A. R; LOUSADA, E. A apropriação de gêneros textuais pelo professor: em direção ao desenvolvimento pessoal e à evolução do "métier". Linguagem em (Dis)curso, Palhoça, SC, v. 10, n. 3, 2010. Disponível em: https://www.scielo.br/scielo.php?pid=S151876322010000300009\&script=sci abstract\&tlng=pt. Acesso em: 05 abr. 2020.

MACHADO, A. R. Por uma concepção ampliada do trabalho do professor. In: GUIMARÃES, A.M.M., MACHADO, A.R. e COUTINHO, A. (org.). $\mathbf{O}$ Interacionismo Sociodiscursivo: Questões epistemológicas e metodológicas. Campinas: Mercado de Letras, 2009. 
MACHADO, A. R; BRONCKART, J.P. De que modo os textos Oficiais prescrevem o Trabalho do Professor? Análise Comparativa de Documentos Brasileiros e Genebrinos. Revista de Documentação de Estudos em Linguística Teórica e Aplicada Delta. São Paulo, vol. 21, n.2, 2005.

SAUJAT, F. O trabalho do professor nas pesquisas em educação: um panorama. In: MACHADO, A. R. (org.). O ensino como trabalho: uma abordagem discursiva. Londrina: Eduel, 2004, p. 3-34.

Recebido em: 07 de outubro de 2020

Aceito em: 17 de março de 2021

Publicado em maio de 2021

Rosivaldo Gomes

E-mail: rosivaldounifap12@gmail.com

ORCID: https://orcid.org/0000-0001-8770-6177

Eulália Vera Lúcia Fraga Leurquin

E-mail: eulaliaufc@gmail.com

ORCID: https://orcid.org/0000-0001-7532-1210 